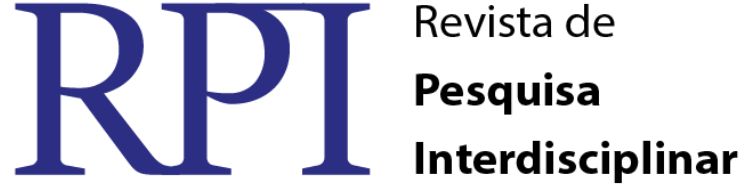

\section{ANÁLISE DA INSERÇÃO DAS TECNOLOGIAS DIGITAIS COMO CONTRIBUIÇÃO NO PROCESSO DE ENSINO E APRENDIZAGEM DO AMBIENTE ESCOLAR VISANDO NOVAS PRÁTICAS PEDAGÓGICAS.}

\author{
Douglas Leão Lopes Torres - Centro Universitário Doutor Leão Sampaio \\ Valesca Leão Jacinto Torres - Centro Universitário Doutor Leão Sampaio
}

\begin{abstract}
RESUMO
As novas tecnologias possuem o intuito de ajudar de forma efetiva os estudantes, quando estes estiverem na escola e nesse momento eles se sentirão estimulados a buscar e socializar com esses recursos de forma a melhorar seu desempenho escolar. Com a inserção de novas tecnologias dentro do ambiente escolar, o docente agora conta com uma nova ferramenta pedagógica bastante útil no processo de ensino-aprendizagem, facilitando assim a disseminação dos conhecimentos entre os discentes. $\mathrm{O}$ uso destas novas tecnologias da comunicação e informação representa uma grande inovação na educação, pois propicia o desenvolvimento das produções em colaboração, podendo instigar o espírito investigativo tanto dos alunos quanto dos professores sendo que estes poderão apropriar-se do uso das tecnologias para mediar os trabalhos dos estudantes, sentindo-se desafiados a buscar condições mais adequadas para o processo de aprendizagem interativo e dinâmico. Portanto, conclui-se que é de fundamental importância que o ambiente escolar insira as novas tecnologias na educação como ferramentas que auxiliem no processo de aprendizagem dos estudantes.
\end{abstract}

Palavras-Chave: Educação. Escola. Tecnologia.

\section{ANALYSIS OF THE INTEGRATION OF DIGITAL TECHNOLOGIES AS CONTRIBUTION IN THE PROCESS OF TEACHING AND LEARNING ENVIRONMENT SCHOOL SEEKING NEW EDUCATIONAL PRACTICES.}

\begin{abstract}
New technologies have in order to help effectively the students while they are at school and at that time they will be encouraged to seek out and socialize with these resources to improve school performance. With the inclusion of new technologies within the school environment, the teacher now has a new useful tool for teaching-learning process, thus facilitating the dissemination of knowledge among students. The use of these new technologies of communication and information is a major innovation in education, because it promotes the development of productions in collaboration, can instigate investigative spirit both students and teachers and that they may take ownership of the use of technology to mediate student work, feeling challenged to seek more suitable conditions for the process of dynamic and interactive learning. Therefore, it is concluded that it is of fundamental importance that the school environment enter the new technologies in education as tools to assist in the students learning process.
\end{abstract}

Keywords: Education. School. Technology. 


\section{INTRODUÇÃO}

Atualmente, cada vez mais a educação vem se aprimorando quanto a novas técnicas de incentivo para educar os estudantes em sala de aula. Esta preocupação para o professor é constante, pois busca sempre a melhor forma de repassar seus conhecimentos. Com a inserção de novas tecnologias dentro do ambiente escolar, o docente agora conta com uma nova ferramenta pedagógica bastante útil no processo de ensino-aprendizagem, facilitando assim a disseminação dos conhecimentos entre os discentes.

Além da contribuição em sala, os avanços tecnológicos também permitem a comunicação fora da escola com seus professores podendo tirar dúvidas mesmo com longas distâncias (FERNANDES et al., 2013).

A tecnologia educacional é um novo instrumento de trabalho que pode propalar na sociedade e principalmente no âmbito escolar, a importância da interação, da pesquisa e da informação tecnológica em todo meio social (SILVA; MENDANHA, 2014).

As novas tecnologias possuem o intuito de ajudar de forma efetiva os estudantes, quando estes estiverem na escola e nesse momento eles se sentirão estimulados a buscar e socializar com esses recursos de forma a melhorar seu desempenho escolar. Com o uso destas, além de facilitar o acesso a novos conhecimentos servem também de base para novas adaptações aos sistemas variados de transmissão de conhecimento de maneira a melhorar, transferir e transformar os fatores complicados com algo mais acessível (SOUZA, I.; SOUZA, L., 2010).

Dessa forma, os educadores devem estar atentos quanto ao uso dos recursos tecnológicos como meios educacionais, pois os mesmos devem ser utilizados de forma correta e eficaz, para que se processe um ensino aprendizagem de forma significativa. A escola deve preparar melhor os docentes para utilizar a tecnologia de forma correta, fazendo um planejamento prévio antes de utilizar os recursos, pois a tecnologia tem sido alvo de grandes destaques e muitos pesquisadores expõem novas visões e reflexões sobre essa temática, com o intuito de compreender os aspectos negativos e positivos do uso do computador como recurso pedagógico.

\section{Desenvolvimento}

RPI Revista de Pesquisa Interdisciplinar, Cajazeiras, v. 1, Ed. Especial, 138 - 144, set/dez. de 2016. 
De acordo com Moreira e Kramer (2007), a promoção de uma educação de qualidade depende de mudanças profundas na sociedade, nos sistemas educacionais e na escola, sendo que se exige que o docente possua condições adequadas ao trabalho pedagógico, tenha conhecimentos e habilidades relevantes e possua informações sobre estratégias e tecnologias que favoreçam o ensinar e o aprender.

\begin{abstract}
A inserção de tecnologias no meio educacional Estimula o professor, por diferentes meios, adaptar-se a circunstâncias variáveis, a produzir em situações mutáveis, a substituir procedimentos costumeiros por "novas" e sempre "fecundas" formas de promover o trabalho docente (MOREIRA; KRAMER, 2007).
\end{abstract}

Com as Novas Tecnologias da Informação abrem-se novas possibilidades à educação exigindo uma nova postura do educador. Com a utilização de redes telemáticas na educação, pode-se obter informações nas fontes, como centros de pesquisa, universidades, bibliotecas, permitindo trabalhos em parceria com diferentes escolas; conexão com alunos e professores a qualquer hora e local, favorecendo o desenvolvimento de trabalhos com troca de informações entre escolas, estados e países, através de cartas, contos, permitindo que o professor trabalhe melhor o desenvolvimento do conhecimento (MERCADO, 1998).

Ser educador requer, portanto, boa capacidade de comunicação. O uso das tecnologias digitais potencializa as habilidades de comunicação do professor (SILVA, 2012). O que a tecnologia traz de novo não é apenas o aparato tecnológico em si, mas a potencialização de novas experiências que os novos meios, principalmente aqueles digitais trazem.

É essencial que o professor se aproprie da gama de saberes advindo com a presença das tecnologias digitais da informação e da comunicação para que estes possam ser sistematizadas em suas práticas pedagógicas, sendo que a aplicação e a mediação que o docente faz em sua prática pedagógica do computador e das ferramentas multimídia em sala de aula, dependem, em parte, de como ele entende esse processo como algo benéfico, que pode ser favorável ao seu trabalho.

A presença das novas tecnologias na escola é defendida por muitos estudiosos, sendo consideradas como ferramentas importantes que auxiliam na condução e na organização dos processos educativos com e para o uso da tecnologia. Principalmente o microcomputador que RPI Revista de Pesquisa Interdisciplinar, Cajazeiras, v. 1, Ed. Especial, 138 - 144, set/dez. de 2016. 
é utilizado como recurso didático com o objetivo de preparar o aluno para uma nova sociedade, cheia de tecnologias, mas, em contrapartida, o posicionamento acarreta problemas quando, na defesa do domínio do aparato tecnológico por parte do discente, em função do fato de o seu não domínio implicar um novo fator de desigualdade e exclusão societárias, não há a preocupação com o entendimento socioistórico desse amparato (OLIVEIRA, 2001).

Certos trabalhos têm demonstrado que o incentivo à criatividade precisa ocorrer em todos os momentos da formação educacional e que as ferramentas educacionais dão suporte a criatividade e ampliam as capacidades dos indivíduos para fazerem descobertas e invenções; Dessa forma, torna-se importante preparar os educadores para que sejam capazes de introduzir tecnologias no ambiente escolar, pois, os alunos envolvidos em atividades que desenvolvam e incentivem habilidades criativas terão mais chances de contribuir com novas descobertas nas mais diversas áreas de ensino (WEBBER; VIEIRA, 2010).

As tecnologias digitais são recursos muito próximos dos alunos, principalmente devido à rapidez de acesso às informações e a forma de acesso randômico, repleto de conexões. Portanto, utilizar tais recursos tecnológicos a favor da educação torna- se o desafio do professor, que precisa se apropriar desses recursos e integrá-los ao seu cotidiano de sala de aula, pois somente formações que permitam reflexão crítica, planejamento e, acima de tudo, a vivência da aplicação das estratégias envolvendo as tecnologias digitais com os alunos, durante o processo de formação, podem trazer benefícios para a educação.

Faz-se necessário que administradores e professores deixem para trás a ideia de que o computador é simplesmente mais um instrumento para ser usado de forma pontual na prática docente e passem a percebê-lo como ferramenta que pode promover desenvolvimento cognitivo e social dos educandos (MAIA; BARRETO, 2012).

É preciso selecionar programas educativos que propiciem conhecimento pedagógico, pois materiais de estímulo-resposta, por exemplo, se não trabalhados adequadamente significarão um retrocesso para o desenvolvimento das crianças (BARBOSA et al., 2014).

A tecnologia deve servir para enriquecer o ambiente educacional, propiciando a construção de conhecimentos por meio de uma atuação ativa, crítica e criativa por parte de alunos e professores (GARCIA, 2013).

Nesse sentido, o educador deve ser um animador de processos de exploração e utilização de materiais de referencia significativa para as crianças. Caso contrário, estará promovendo uma aprendizagem passiva desprovida de sentidos. A criança precisa ser RPI Revista de Pesquisa Interdisciplinar, Cajazeiras, v. 1, Ed. Especial, 138 - 144, set/dez. de 2016. 
estimulada a encontrar respostas diversas e espaço para a criação. O professor necessita saber lidar com as tecnologias digitais, a fim de promover a interatividade, a ajuda mútua que contribuam no desenvolvimento das crianças.

Na Educação Infantil, o uso dessas tecnologias deve ter um caráter educativo, por isso precisam estar inseridas no projeto politico pedagógico da escola, uma vez que as tecnologias digitais não devem ser entendidas como ferramentas, mas como proposta pedagógica, contribuindo em aprendizagens relevantes e socialmente significativas.

O uso destas novas tecnologias da comunicação e informação representa uma grande inovação na educação, pois propicia o desenvolvimento das produções em colaboração, podendo instigar o espírito investigativo tanto dos alunos quanto dos professores sendo que estes poderão apropriar-se do uso das tecnologias para mediar os trabalhos dos estudantes, sentindo-se desafiados a buscar condições mais adequadas para o processo de aprendizagem interativo e dinâmico.

Alguns estudos como o de Barreto (2004) Relata que estas tecnologias acarretam uma precarização do trabalho docente, sendo que quanto maior a presença da tecnologia, menor a necessidade do trabalho humano, prevendo-se cada vez menos professores e mais alunos, sob a alegação de que o desempenho dos últimos depende menos da formação dos primeiros e mais dos materiais utilizados.

Barreto et al.(2006) relata a coexistência de duas tendências que divergem entre si, sendo que em seu estudo diz que a inclusão das mídias digitais no processo de ensino acarreta uma tendência à virtualização que aponta para o deslocamento da dimensão presencial para a virtual, uma nova relação educativa na comunidade virtual, rompendo com a assimetria presente na escola e a quebra do binômio ensino-aprendizagem, privilegiando apenas o segundo elemento do par, pensado como "autoaprendizagem".

Entretanto, outros autores reforçam a ideia de que seria incoerente não incorporar as tecnologias no processo de formação dos futuros cidadãos, principalmente quando consideramos que esses novos cidadãos são nativos de um mundo naturalmente composto por tecnologias telemáticas (LOPES; MONTEIRO; MILL, 2014).

A introdução deste aparato tecnológico no dia a dia do professor é hoje uma realidade. A disseminação do acesso à Internet e a constante inovação tecnológica trouxeram a tecnologia para dentro da sala de aula. Esses

RPI Revista de Pesquisa Interdisciplinar, Cajazeiras, v. 1, Ed. Especial, 138 - 144, set/dez. de 2016. 
recursos vão além do ensino presencial e propiciam a expansão da Educação a Distância- EAD (BARRETO et al., 2006).

Santos e Mortimer (2000) diz que a educação tecnológica é importante para o estudante, mas uma educação que se limite ao uso de novas tecnologias e à compreensão de seu funcionamento é alienante, pois contribui para manter o processo de dominação do homem pelos ideais de lucro a qualquer preço, não contribuindo para a busca de um desenvolvimento sustentável.

\section{Conclusão}

Portanto, conclui-se que é de fundamental importância que o ambiente escolar insira as novas tecnologias na educação como ferramentas que auxiliem no processo de aprendizagem dos estudantes. É fundamental que sejam implantados novos projetos na escola que incentivem o uso da tecnologia a fim de aprimorar o conhecimento e facilitar a dinamização dos conteúdos em sala de aula.

\section{REFERÊNCIAS}

BARBOSA, Gilvana Costa; FERREIRA, Márcia Maria Guimarães de Almeida, BORGES , Luzineide Miranda, e SANTOS, Adilson Gomes dos. "Tecnologias Digitais: Possibilidades e Desafios na educação infantil.” Revista de Ensino Superior a Distância, 2014: 2888-2899.

BARRETO, Raquel Goulart. “Tecnologia e Educação: Trabalho e formação docente.” Revista Educação \& Sociedade, 2004: 1181-1201.

BARRETO, Raquel Goulart; GUIMARÃES, Glaucia Campos, MAGALHÃES , Ligia Karam Corrêa de, e LEHER , Elizabeth Menezes Teixeira. "As tecnologias da informação e da comunicação na formação de professores.” Revista Brasileira de Educação, 2006: 31-43.

FERNANDES, Gabriela doCarmo et al. "O uso da tecnologia em prol da educação: Importância, benefícios e dificuldades encontradas por instituições de ensino e docentes com a integração de novas tecnologias à educação.” Revista Saber Digital, 2013: 140- 148.

GARCIA, Fernanda Wolf. "A importância do uso das tecnologias no processo de ensinoaprendizagem.” Revista Educação a Distância, 2013: 25-48.

LOPES, Ana Helena Ribeiro Garcia de Paiva, MONTEIRO, Maria Iolanda e MILL, Daniel Ribeiro Silva. "Tecnologias digitais no contexto escolar: Um estudo bibliométrico sobre seus usos, suas potencialidades e fragilidades.” Revista Eletrônica de Educação, 2014: 30-43. 
MAIA, Dennys Leite, e BARRETO, Marcilia Chagas. "Tecnologias digitais na educação: uma análise das políticas públicas brasileiras ." Revista Educação, Formação \& Tecnologias, 2012: 47-61.

MERCADO, Luís Paulo Leopoldo. "Formação docente e novas tecnologias." IV Congresso RIBIE, 1998: 01-08.

MOREIRA, Antonio Flavio Barbosa e KRAMER Sonia. "Contemporaneidade, educação e tecnologia.” Revista Educação \& Sociedade, 2007: 1037-1057.

OLIVEIRA, Maria Rita Neto Sales. "Do mito da tecnologia ao paradigma tecnológico; a mediação tecnológica nas práticas didático-pedagógicas.” Revista Brasileira de Educação, 2001: 101-107.

SANTOS, Wildson Luiz Pereira dos e MORTIMER, Eduardo Fleury. "Uma análise de pressupostos teóricos da abordagem C-T-S (Ciência - Tecnologia - Sociedade) no contexto da educação brasileira.” Revista Educação \& Sociedade, 2002: 01-23.

SILVA, Eli Lopes da. "Tecnologias Digitais na Educação: Dois anos de pesquisa com webquest na prática pedagógica- Desafios e possibilidades." Seminário de pesquisa em educação da região Sul, 2012: 01-15.

SILVA, Marcos Nunes da e MENDANHA, José Francisco. "A importância da ferramenta tecnológica no contexto social e educacional.” Revista Científica do ITPAC, 2014: 19836708 .

SOUZA, Isabel Maria Amorim de e SOUZA, Luciana Virgília Amorim de. "O uso da tecnologia como facilitadora da aprendizagem do aluno na escola." Revista Fórum Identidades, 2010: 127-142.

WEBBER, Carine Geltrudes e VIEIRA, Martha Barcelos. "Tecnologias Digitais na Educação: Colaboração e criatividade em sala de aula.” 2010: 166-177. 